\title{
PREDISPOSIÇÃO AO FLUXO: PERCEPÇÃO DOS PRATICANTES DO BASQUETE EM CADEIRA DE RODAS
}

\author{
Daniel Alvarez Pires \\ Universidade Federal do Pará, Castanhal, Pará, Brasil. \\ Jadson Geovane de Brito Oliveira \\ Universidade Federal do Pará, Castanhal, Pará, Brasil. \\ Anselmo de Athayde Costa e Silva \\ Universidade Federal do Pará, Castanhal, Pará, Brasil.
}

\begin{abstract}
Resumo
O objetivo do presente estudo foi investigar a percepção de fluxo em 15 paratletas de basquetebol em cadeira de rodas do sexo masculino. Para isto, foi utilizada a "Escala de Predisposição ao Fluxo" e a análise de dados foi realizada por meio de estatística descritiva e análise de correlação para estabelecer a relação entre as dimensões do estado de fluxo. De modo geral verificamos que os paratletas vivenciam o estado de fluxo, sendo que experiência autotélica e clareza de metas foram as dimensões com maior prevalência entre os praticantes da modalidade, assim como concentração na tarefa apresentou-se correlacionada com as dimensões fusão entre ação e consciência, metas claras, percepção de controle, e experiência autotélica.
\end{abstract}

Palavras-Chave: Psicologia do Esporte. Motivação. Basquetebol em Cadeira de Rodas.

\section{FLOW PREDICTION: PERCEPTION OF WHEELCHAIR BASKETBALL PRACTICERS}

\begin{abstract}
The aim of the present study was to investigate the perception of flow in 15 male wheelchair basketball athletes. For this, the "Flow Predisposition Scale" was used and the data analysis was performed through descriptive statistics and correlation analysis to establish the relationship between the flow feeling dimensions. In general, we verified that the athletes experience flow, specially autothelic experience and clarity of goals, the dimensions with greater prevalence among the practitioners of the modality, as well as concentration on task was correlated with the dimensions fusion between action and consciousness, clear goals, perception of control, and autotelic experience.
\end{abstract}

Keywords: Psychology, Sports. Motivation. Wheelchair Basketball. 


\section{DISPOSICIÓN A FLUJO: PERCEPCIÓN DE LOS PRACTICANTES DE BALONCESTO EN SILLA DE RUEDAS}

\section{Resumen}

El objetivo del presente estudio fue investigar la percepción de flujo en 15 atletas de baloncesto en silla de ruedas del sexo masculino. Para ello, se utilizó la "Escala de Predisposición al Flujo" y el análisis de datos fue realizado por medio de estadística descriptiva y análisis de correlación para establecer la relación entre las dimensiones del estado de flujo. En general verificamos que los atletas experimentan el estado de flujo, siendo que la experiencia autotélica y la claridad de metas fueron las dimensiones con mayor prevalencia entre los practicantes de la modalidad, así como concentración en tarea se presentó correlacionada con las dimensiones de fusión entre acción y conciencia, metas claras, percepción de control, y experiencia autotélica.

Palabras Clave: Psicología del Deporte. Motivación. Baloncesto en Silla de Ruedas

\section{Introdução}

O esporte de alto rendimento é um fenômeno de entretenimento que atrai a atenção de grande público. Neste caso, o objetivo daqueles envolvidos com a prática do esporte consiste em alcançar recordes e vitórias, privilegiando o desempenho esportivo (COSTA, 2007). Diante desse contexto, pesquisadores das ciências do esporte têm trabalhado ativamente na produção de conhecimento para possibilitar o sucesso esportivo. Um exemplo concreto é a psicologia do esporte, que lida com fatores comportamentais do indivíduo que influenciam o rendimento esportivo. Dentre os variados objetos de estudo da psicologia do esporte é possível citar o estado de fluxo ou flow feeling em inglês, que fora descrito inicialmente por Mihaly Csikszentmihalyi na década de 1970 (MIRANDA; BARA FILHO, 2008).

$\mathrm{O}$ estado de fluxo se refere a um estado mental no qual os indivíduos aparentam fluir no decorrer da tarefa, em uma experiência em que a concentração é elevada de tal forma que nenhuma atenção é voltada para pensamentos irrelevantes ou problemas externos. Nesse contexto, o indivíduo apresenta esforço produtivo e é motivado intrinsecamente. Esse estado é acompanhado por diferentes emoções relacionadas a comportamentos positivos e funcionais (GOMES et al., 2012a; KOEHN; MORRIS; WATT, 2014; SWANN et al., 2012).

Segundo Miranda e Bara Filho (2008), algumas atividades apresentam características que provocam a experiência máxima no praticante. O esporte representa uma boa oportunidade para a manifestação do estado de fluxo, pois sua prática está associada a elevados níveis de envolvimento, desejo, desafio e prazer em comparação com outras atividades (JACKSON, 1996). Estudos no contexto esportivo buscam confirmar os fatores associados a um estado psicológico avaliado como ideal, ou seja, a obtenção dos melhores resultados por meio do estado ótimo do atleta (GOMES et al., 2012b; MIRANDA JUNIOR, 2012; VIEIRA et al., 2011).

Características individuais, como o perfil motivacional, permitem aos atletas alcançarem os níveis ótimos no decorrer de atividades e determinam a facilidade do indivíduo para chegar ao estado de fluxo. Segundo Samulski (2009), a motivação esportiva é um processo ativo e intencional direcionado a um objetivo, dependente da interação de fatores intrínsecos ou extrínsecos. Dessa forma, o indivíduo motivado intrinsecamente é aquele cujo envolvimento e constância na atividade acontecem porque a tarefa em si é interessante e produz satisfação. Quando a pessoa é motivada intrinsecamente, ela manifesta tal comportamento de modo voluntário, sem a ocorrência de recompensas materiais e/ou de pressões externas. Nessa mesma linha de pensamento, o sujeito motivado extrinsecamente é aquele que desempenha 
uma atividade ou tarefa tendo em vista recompensas externas ou sociais, tais como receber elogios ou apenas evitar punições (RYAN; DECI, 2000). No contexto esportivo, atletas e paratletas apresentam predisposição ao estado de fluxo quando se encontram motivados intrinsecamente. Tal motivação prediz a necessidade da boa execução de tarefas, sem dependência de fatores externos para desenvolver o seu melhor desempenho (MASSARELLA; WINTERSTEIN, 2009).

Portanto, investigações sobre a natureza desse estado e sua manifestação são importantes para a pesquisa e a intervenção profissional na psicologia do esporte (SWANN et $a l .$, 2015). O estado de fluxo apresenta nove dimensões, as quais estão dispostas na Figura 1.

De acordo com Csikszentmihalyi (1999), o indivíduo que apresenta personalidade autotélica tem maior predisposição para alcançar o estado de fluxo. Tal personalidade denota uma pessoa que não visa recompensas externas na realização de atividades, e sim o prazer de poder fazê-las. Macías et al. (2015) afirmam que pessoas autotélicas apresentam um conjunto de características que facilitam a ocorrência do fluxo: alta curiosidade, motivação intrínseca, persistência, autonomia e independência sobre os fatores externos.

As dimensões do estado de fluxo variam de acordo com o tipo de manifestação esportiva, além da variação individual. Enquanto há uma produção consistente de estudos a respeito do estado de fluxo em esportes convencionais, aparentemente existe lacuna na literatura sobre o tema em outras manifestações esportivas. É o caso do esporte adaptado, que começou a ser praticado de forma organizada após a segunda Guerra Mundial, por ter seu uso indicado na reabilitação de soldados e cidadãos com deficiência adquirida no conflito (ARAÚJO, 1998). Atualmente, o esporte adaptado é um fenômeno complexo que pode agregar objetivos diferentes em função das expectativas de seus praticantes (COSTA E SILVA et al., 2013).

$\mathrm{O}$ basquete em cadeira de rodas é uma das modalidades mais antigas entre as modalidades coletivas adaptadas e se caracteriza por ser um esporte em que ocorre interação dos paratletas com o meio ambiente (torcida, adversários e outros). Com isso, existe a construção de um ambiente aleatório, imprevisível e adverso (BALBINOTTI; SALDANHA; BALBINOTTI, 2009). Tais características determinam uma estrutura organizada e desafiante que, por conseguinte, favorece o estado de fluxo (OLIVEIRA; MIRANDA, 2015). Embora se trate de uma modalidade popular, pois existem cerca de 80 equipes no Brasil, segundo informações da Confederação Brasileira de Basquetebol em cadeira de Rodas (CBBC, 2015), até o presente momento não se tem registro de investigações acerca do estado de fluxo em paratletas da modalidade, de modo que não há caracterização da relação entre as dimensões do estado de fluxo nesta população. Estudos de verificação do estado de fluxo possibilitarão a compreensão da percepção de cada uma das dimensões de fluxo em paratletas dessa modalidade, levando a possíveis adaptações no planejamento dos treinamentos e competições, de modo a potencializar a ocorrência desse fenômeno benéfico ao bem-estar e ao desempenho.

Diante da realidade brasileira, em que o esporte paralímpico de alto rendimento está concentrado nas regiões sudeste e sul, surge uma carência de estudos sobre como os aspectos psicológicos se manifestam em profissionais esportivos da região norte, especialmente os paratletas. Assim, o objetivo do presente estudo foi investigar a percepção do nível de fluxo dos praticantes do basquete em cadeira de rodas, para possibilitar a compreensão desse fenômeno em pessoas com deficiência (PCD) que praticam esporte coletivo. 
Figura 1. As dimensões do estado do fluxo.

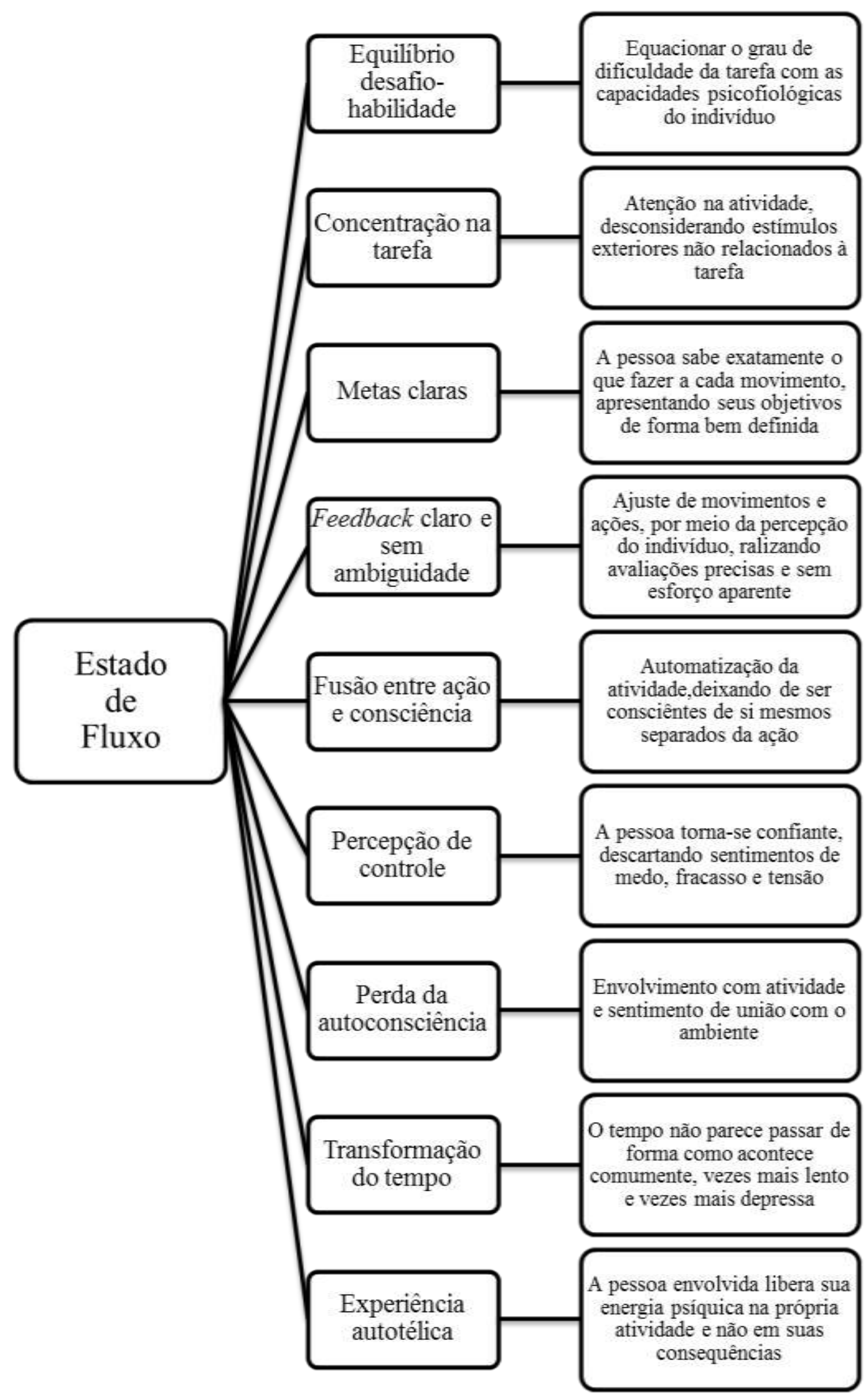

Fonte: Elaborada pelos autores a partir de adaptações de Gomes et al. (2012a), Kawabata e Evans (2016), Koehn, Morris e Watt (2013), Oliveira e Miranda (2015). 


\section{Material e Método}

\section{Amostra e Cuidados Éticos}

A amostra do presente estudo foi constituída de 15 paratletas do sexo masculino, que representam uma equipe de basquete em cadeira de rodas. Todos os participantes são PCD. A equipe participa da $1^{\mathrm{a}}$ divisão do campeonato nacional, além de outras competições ao longo do ano, tais como campeonato estadual, regional e outros eventos locais. A média de idade foi de 32,3 anos $( \pm 10,1$ anos $)$ e o tempo médio de prática da modalidade foi de 10,5 anos $( \pm 6,4$ anos).

Foram incluídos no estudo apenas os paratletas ativos, que mantém uma frequência regular de dois treinos semanais há pelo menos dois anos. Foram excluídos da amostra os paratletas com menos de dois anos de prática na modalidade, pois a exigência geral, em destaque a técnica e a tática do jogo de basquetebol em cadeira de rodas, implica que para se ter o controle dos fundamentos do jogo, bom nível de concentração para o desenvolvimento da tática de jogo e atendimento de outras demandas, exige-se um tempo de prática maior. Relativamente, quanto maior o tempo de prática, maiores as possibilidades de fluir (OLIVEIRA; GOMES; MIRANDA, 2015; OLIVEIRA; MIRANDA, 2015).

O estudo foi realizado em conformidade com a Resolução 466/12 do Conselho Nacional de Saúde que trata sobre pesquisas com seres humanos, bem como foi aprovado pelo Comitê de Ética em Pesquisa do Hospital Universitário João de Barros Barreto, sob o parecer 65796316.3.0000.0017. A identidade dos participantes foi preservada e os dados coletados foram utilizados apenas para o objetivo do estudo. Os voluntários que concordaram em participar do estudo assinaram o Termo de Consentimento Livre e Esclarecido (TCLE).

\section{Instrumento}

Para a coleta dos dados foi utilizada a Escala de Predisposição ao Fluxo (EPF), versão traduzida e validada por Gomes (2014) para o idioma português da Dispositional Flow Scale (JACKSON et al., 1998). Tal escala é constituída por 36 questões respondidas por meio de uma escala Likert de 1 (nunca) a 5 (sempre) que representam as nove dimensões do fluxo e o fluxo global. O participante é direcionado a pensar sobre a frequência na qual comumente experimenta as dimensões do fluxo na atividade praticada. Os resultados das dimensões do fluxo são obtidos por meio do valor médio dos quatro itens associados às mesmas, enquanto que o valor do fluxo global é obtido por meio da média das respostas de todos os itens do instrumento. No estudo de validação da escala para o idioma português, o coeficiente Alpha de Cronbach das dimensões de fluxo variou entre 0,65 e 0,89 , apontando para uma consistência interna satisfatória do instrumento (GOMES, 2014).

\section{Procedimentos}

Inicialmente, os autores solicitaram permissão para a realização do estudo junto à diretoria da equipe. Em seguida, foram agendados os momentos para a coleta de dados, que foi realizada no ambiente de treinamento da equipe, antes das sessões de treinos, em sala reservada, livre de ruídos e interferências externas. O primeiro autor, dotado de experiência prévia tanto em coleta de dados com instrumentos psicométricos quanto em esporte adaptado, foi o único responsável pela coleta de dados. O mesmo reforçou informações sobre riscos, voluntariedade na participação e sigilo com relação aos dados. Finalmente, os participantes responderam aos instrumentos, com duração média de 20 minutos. 


\section{Análise dos Dados}

Os dados referentes à percepção das dimensões de fluxo foram apresentados por meio da estatística descritiva. Para a verificação da correlação entre as nove dimensões avaliadas pela escala e o fluxo global, foi utilizado o coeficiente rho de Spearman. O valor crítico de rho $>0,40$ foi considerado aceitável para as correlações, pois corresponde ao limite inferior da intensidade moderada para a correlação entre variáveis $(0,40$ a 0,69$)$, sendo que de 0,70 a 1,0 há forte intensidade para as correlações (DANCEY; REIDY, 2013; THOMAS; NELSON; SILVERMAN, 2007). Todos os procedimentos foram realizados por meio do pacote estatístico GraphPad Prism, versão 7 (GraphPad Software Inc., San Diego, CA, EUA). O nível de significância adotado foi de $\mathrm{p} \leq 0,05$.

\section{Resultados}

A Tabela 1 apresenta as médias e os desvios-padrão das dimensões do estado de fluxo e do fluxo global. Destacam-se como médias mais elevadas e, portanto, mais frequentes, as dimensões: experiência autotélica, indicando que os paratletas percebem a atividade como prazerosa e edificante; e metas claras, evidenciando que os paratletas possuem noção precisa do que pretendem alcançar, bem como do que precisam fazer. De maneira geral, os resultados indicam que os paratletas experimentam o fluxo durante sua prática, pois apresentam média do fluxo global que corresponde à intensidade "frequentemente". Por outro lado, as dimensões menos percebidas foram: transformação do tempo, indicando que os paratletas não perceberam o tempo passar mais depressa ou mais devagar que o normal; e perda da autoconsciência, evidenciando que os paratletas não apresentaram despreocupação em relação a si mesmos e suas ações. Com exceção da perda da autoconsciência, todas as dimensões possuem médias acima de 3 pontos.

Tabela 1. Estatística descritiva das dimensões do fluxo $(n=15)$ e intensidade associada às médias.

\begin{tabular}{lcc}
\multicolumn{1}{c}{ Dimensões } & $\mathbf{M} \pm \mathbf{D P}$ & Intensidade \\
\hline Experiência autotélica & $4,87 \pm 0,25$ & Frequentemente \\
Metas claras & $4,62 \pm 0,41$ & Frequentemente \\
Concentração na tarefa & $4,55 \pm 0,46$ & Frequentemente \\
Feedback claro e sem ambiguidade & $4,47 \pm 0,47$ & Frequentemente \\
Equilíbrio desafio-habilidade & $4,38 \pm 0,57$ & Frequentemente \\
Percepção de controle & $4,30 \pm 0,90$ & Frequentemente \\
Fusão entre ação e consciência & $3,92 \pm 0,86$ & Algumas vezes \\
Transformação do tempo & $3,25 \pm 0,92$ & Algumas vezes \\
Perda da autoconsciência & $2,90 \pm 1,48$ & Raramente \\
Fluxo global & $4,14 \pm 0,37$ & Frequentemente \\
\hline
\end{tabular}

A Tabela 2 apresenta as correlações entre as nove dimensões e o fluxo global. Observamos que quatro das nove dimensões do estado de fluxo não se correlacionam de maneira significativa com o fluxo global: equilíbrio desafio-habilidade, feedback claro e sem ambiguidade, transformação do tempo e experiência autotélica (absorção completa do indivíduo pela tarefa). Três dimensões se correlacionam de forma moderada, positiva e significativa com o fluxo global: perda da autoconsciência, fusão entre ação e consciência e metas claras. As dimensões percepção do controle e concentração na tarefa apresentaram correlações fortes, positivas e significativas em relação ao fluxo global, evidenciando a relevância da autoconfiança e da atenção à tarefa para o alcance do estado de fluxo. 
Ainda na Tabela 2, observamos a presença de correlação forte, positiva e significativa entre as dimensões fusão entre ação e consciência e percepção de controle. As dimensões metas claras x percepção do controle, concentração na tarefa x percepção de controle, metas claras x concentração na tarefa, equilíbrio desafio-habilidade x feedback claro e sem ambiguidade, fusão entre ação e consciência x concentração na tarefa e concentração na tarefa $\mathrm{x}$ experiência autotélica apresentaram correlações moderadas, positivas e significativas entre si.

Tabela 2. Correlação entre as dimensões (valor de $r h o)(\mathrm{n}=15)$.

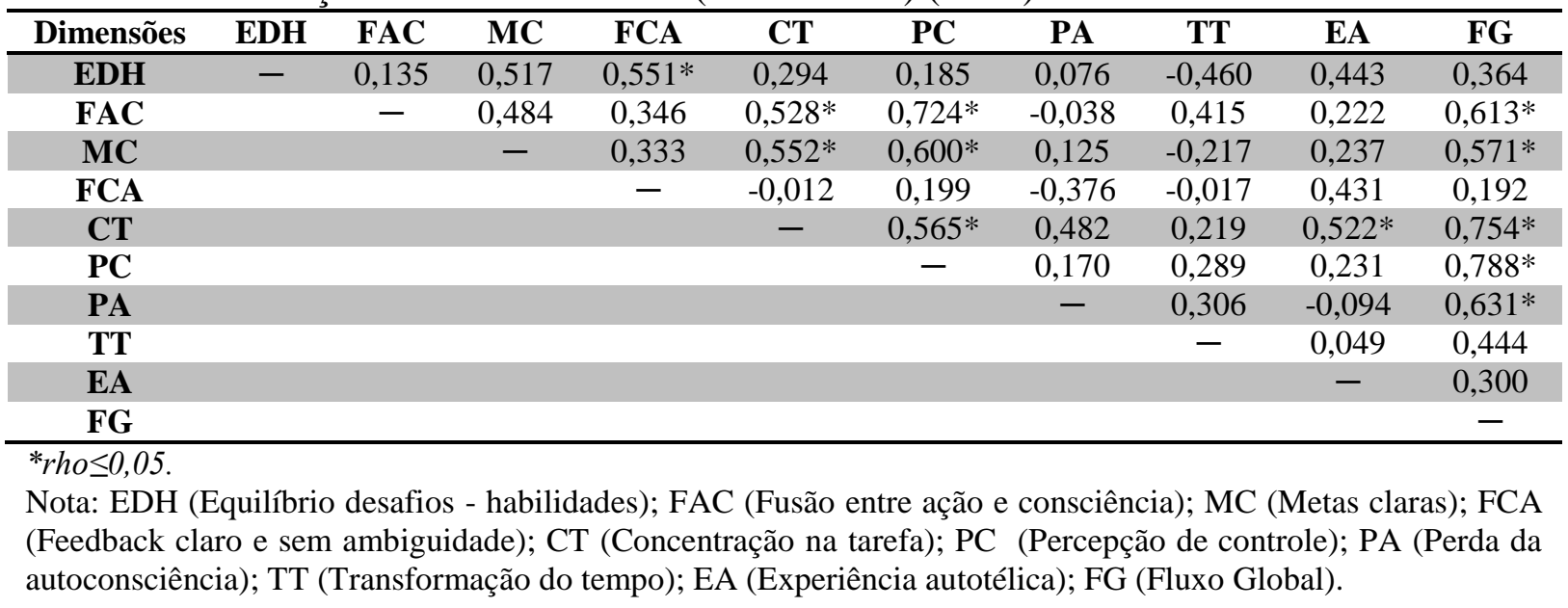

\section{Discussão}

O presente estudo teve como objetivo central investigar a percepção do nível de fluxo dos paratletas de basquete em cadeira de rodas. Observamos que os paratletas apresentaram resultados elevados em seis dimensões do fluxo, bem como na percepção do estado de fluxo global, resultados indicativos da vivência do estado de fluxo. Resultados semelhantes foram observados nos estudos de Gomes et al. (2012a) e Oliveira, Gomes e Miranda (2015), ambos envolvendo jovens atletas de basquete.

A dimensão experiência autotélica foi a mais percebida pelos participantes. A mesma é caracterizada por foco absoluto em uma atividade específica até o ponto em que o indivíduo é totalmente absorvido por ela, não sendo interrompido por qualquer outro pensamento ou emoção, sentindo-se parte da atividade (MIRANDA; BARA FILHO, 2008). Paratletas de esportes adaptados podem perceber a prática esportiva como oportunidade de aquisição da autonomia financeira e como uma das poucas vias de ascensão social (COSTA E SILVA et al., 2013). Nesse contexto, o significado do esporte para a PCD contribui para que a mesma se torne focada na modalidade, confirmando a presença da personalidade autotélica.

A segunda dimensão mais percebida se refere às metas claras. No estado de fluxo, o atleta tem absoluta nitidez a respeito do objetivo a ser atingido e do que é necessário para realizar a atividade com sucesso e, consequentemente, fluir (OLIVEIRA; MIRANDA, 2015). Observou-se que os paratletas possuem clareza de metas no esporte. Assim, os mesmos apresentam foco absoluto nos treinamentos, em busca do aprimoramento de suas técnicas, para que eles possam apresentar desempenho elevado e ficar entre os melhores na modalidade em questão. O significado do esporte como única fonte de ascensão social para a PCD contribui para o estabelecimento de objetivos realistas, porém desafiadores, bem como para a disciplina no cumprimento dos mesmos (COSTA E SILVA et al., 2013).

Por outro lado, a dimensão transformação do tempo obteve a segunda menor média entre os participantes. Uma possível explicação consiste no fato do basquetebol possuir tempo de jogo cronometrado de modo regressivo. Desse modo, os praticantes estão atentos ao 
cronômetro durante boa parte da partida, dificultando a percepção de transformação do tempo. Outra explicação está associada ao fato de ser um jogo com muitas paradas entre os tempos (quartos de jogo) e os pedidos técnicos, momentos que interrompem o estado de fluxo.

Diferentemente do presente estudo, manifestações de fluxo foram observadas em jovens atletas de basquetebol. Em um determinado momento do jogo, atletas sentiram que o tempo estava acelerado e consequentemente o jogo e/ou os períodos acabaram rapidamente. Já em outra situação de jogo, atletas perceberam o tempo de forma desacelerada, acarretando em uma maior precisão no arremesso, tornando a ação mais efetiva (OLIVEIRA; GOMES; MIRANDA, 2015).

A relação dos atletas com o tempo é individual, pois a dimensão transformação do tempo pode ser sentida de diversas formas, originando-se a partir da percepção do atleta. Isso pode acontecer pelo fato de que a percepção dessa dimensão pode se alterar conforme o esporte praticado, uma vez que a especificidade das modalidades determina o sentimento de passagem do tempo. No triatlo, por exemplo, o participante realiza cada etapa (natação, ciclismo e corrida) em sequência específica, buscando a obtenção do seu melhor tempo. Neste caso, para alcançar o estado de fluxo, o participante precisa sentir o tempo passar de forma mais acelerada do que o real, como se a prova praticada fosse mais curta, tendo assim um menor desgaste psicofisiológico. Em contrapartida, um nadador de 100 metros livres tem a percepção alterada da dimensão transformação do tempo. O mesmo precisa perceber o tempo passando de forma muito lenta, pois a duração da prova é muito curta e com isso, ao perceber que tudo está mais devagar que a realidade, facilita-se a execução dos movimentos do atleta, tornando a ação mais efetiva (GARCÍA et al., 2008).

A dimensão perda da autoconsciência foi a menos percebida pela amostra. Oliveira, Gomes e Miranda (2015) também observaram escassos registros dessa dimensão em jovens atletas de basquetebol. $\mathrm{O}$ fato de os paratletas não terem perdido a percepção do self, fator que caracteriza essa dimensão (CSIKSZENTMIHALYI, 1999), pode ser um indicativo de autoconsciência elevada e esforço intenso, elementos constitutivos do clutch, considerado um estado mais complexo e dinâmico que o fluxo, cuja ocorrência na literatura é recente (SWANN; CRUST; VELLA, 2017; SWANN et al., 2016). Assim como o fluxo, o clutch também está associado ao desempenho elevado, porém em circunstâncias em que o atleta está consciente que seu desempenho ocorre durante uma situação de pressão. Por isso, avalia o contexto como desafiador, enfrentando o estresse e os esforços intensos da tarefa.

Quando as dimensões do fluxo se manifestam tanto individualmente quanto de modo sinérgico entre os atletas de uma determinada equipe de esportes coletivos, pode ocorrer o estado de fluxo coletivo, observado nos contextos do basquete (OLIVEIRA; GOMES; MIRANDA, 2015) e futebol (BAKKER et al., 2011). Nessa perspectiva, comportamentos e atitudes de atletas poderão contagiar seus pares, pois todos estão vivenciando a existência de elementos em comum (técnicos, adversários, ambiente) no mesmo momento (BAKKER et al., 2011).

Quanto às correlações entre as dimensões do fluxo e o fluxo global, foram percebidas correlações fracas entre a dimensão transformação do tempo e as demais dimensões, indicando que a alteração do sentido do tempo não é tão acentuada para as experiências de fluxo dos paratletas de basquete em cadeira de rodas. Conforme relatamos anteriormente, esse achado pode estar associado ao fato de uma partida de basquete em cadeira de rodas possuir o tempo cronometrado, dificultando o alcance do estado de fluxo e aumentando a possibilidade de sua interrupção.

Por sua vez, a correlação entre as dimensões equilíbrio desafio-habilidade e feedback claro e sem ambiguidade sugere que, para melhor retorno positivo do paratleta sobre a atividade, faz-se necessário o entendimento das demandas imprescindíveis para a sua execução, percebendo-se capaz de atendê-las. Com isso, o equilíbrio entre a percepção a 
respeito das exigências da atividade (treinamento físico, técnico, tático e psicológico, viagens e competições) e sua capacidade de corresponder a elas pode ser crucial para que o atleta apresente uma resposta imediata a ponto de fazer reparos precisos e instantâneos, atingindo o resultado desejado (GOMES et al., 2012a).

A correlação entre as dimensões concentração na tarefa e fusão entre ação e consciência sugere que, para alcançar o estado de fluxo, o paratleta precisa compreender a tarefa, tomando consciência da mesma, buscando encontrar o equilíbrio necessário para obter o seu melhor e atingir o estado de fluxo. Segundo Miranda e Bara Filho (2008), o atleta percebe os seus movimentos realizando uma fusão corpo-mente sem precisar atentar para seus movimentos, pois o controle é interno ao indivíduo, sem perda de concentração.

As dimensões fusão entre ação e consciência e percepção de controle se correlacionam, indicando que o paratleta autoconfiante nas suas habilidades sente-se consciente das ações a serem desenvolvidas para melhor desempenhar as tarefas. Assim, o atleta descarta a percepção de medo, fracasso e outras sensações negativas (CSIKSZENTMIHALYI, 1999; MIRANDA; BARA FILHO, 2008).

$O$ fato de metas claras, concentração na tarefa e percepção de controle se correlacionarem entre si indica a importância de se ter os objetivos claros para um melhor resultado, levando em consideração a concentração para não perder o foco, além da percepção de domínio da tarefa para o alcance do seu melhor desempenho (GOMES et al., 2012a, 2012b).

A correlação entre as dimensões experiência autotélica e concentração na tarefa sugere que a atividade competitiva está associada à forte percepção de controle do atleta sobre suas ações, liberando toda sua energia psíquica com foco na melhora do desempenho, desconsiderando estímulos externos (GOMES et al., 2012a). Essa correlação reforça que o componente intrínseco da motivação está mais associado à percepção de fluxo do que o componente extrínseco, pois a motivação intrínseca interfere positivamente no empenho, engajamento, assiduidade, tempo de permanência e satisfação do indivíduo na prática esportiva. A experiência intrinsecamente gratificante revela o caráter autossustentador da atividade, no qual o momento presente é fonte de prazer, em detrimento do aprisionamento gerado pela expectativa de recompensas futuras (MASSARELLA; WINTERSTEIN, 2009).

O presente estudo contribui com a literatura em psicologia do esporte ao investigar a percepção de fluxo em paratletas de basquete em cadeira de rodas, evidenciando a manifestação das dimensões experiência autotélica e estabelecimento de metas claras. Sugerimos a inclusão de mulheres em estudos futuros, possibilitando a compreensão do efeito da variável sexo sobre o estado de fluxo nesta modalidade.

\section{Conclusão}

O estudo apresenta evidências que sugerem que paratletas de basquete em cadeira de rodas têm predisposição para alcançar o estado de fluxo, pois os mesmos apresentam indicadores elevados para algumas das dimensões do fluxo no contexto esportivo, sentindo-se paratletas autotélicos, uma vez que a atividade é gratificante. Para eles, a própria experiência é a fonte mais importante de entusiasmo e envolvimento, bem como as metas estabelecidas são claras e definidas.

\section{Referências}

ARAÚJO, P. F. Desporto Adaptado no Brasil: Origem, Institucionalização e Atualidade. Brasília: Publicações INDESP, 1998. 
BAKKER, A. B. et al. Flow and performance: A study among talented Dutch soccer players. Psychology of Sport and Exercise, Amsterdam, v. 12, n. 4, p. 442-450, 2011.

BAlBinOtTI, M. A. A.; SAlDANHA, R. P.; BALBINOTTI, C. A. A. Dimensões motivacionais de basquetebolistas infanto-juvenis: um estudo segundo sexo. Motriz, Rio Claro, v. 15, n. 2, p. 318-329, 2009.

CBBC. Confederação Brasileira de Basquete em Cadeira de Rodas. Ranking CBCC 2015. 2015. Disponível em: 〈http://www.cbbc.org.br/conteudo/anexo/c4ccb8d9391416580ef1ba7134a71d38.pdf〉. Acesso em: 15 dez. 2017.

COSTA E SILVA, A. A. et al. Esporte adaptado: abordagem sobre os fatores que influenciam a prática do esporte coletivo em cadeira de rodas. Revista Brasileira de Educação Física e Esporte, São Paulo, v. 27, n.1, p. 1-9, 2013.

COSTA, M. M. Esporte de alto rendimento: Produção social da modernidade - o caso do vôlei de praia. Sociedade e Estado, Brasília, v. 22, n 1, p. 35 - 69, 2007.

CSIKSZENTMIHALYI, M. A descoberta do fluxo: a psicologia do envolvimento com a vida cotidiana. São Paulo: Rocco, 1999.

DANCEY, C. P.; REIDY, J. Estatística sem matemática para a psicologia. 5 ed. Porto Alegre: Penso, 2013.

GARCÍA, T. et al. Psychometric properties of the Spanish version of the Flow State Scale. The Spanish Journal of Psychology, Cambridge, v. 11, n.2, p. 660-669, 2008.

GOMES, S. S. et al. Fluxo no para-atletismo. Motricidade, Santa Maria da Feira, v. 8, n. S2, p. 985-992, 2012a.

GOMES, S. S. et al. O fluxo no voleibol: relação com a motivação, autoeficácia, habilidade percebida e orientação às metas. Revista da Educação Física/UEM, Maringá, v. 23, n. 3, p. 379-387, 2012b.

GOMES, S. S. Evidências psicométricas da escala de predisposição ao fluxo (DFS-2) para brasileiros. 2014. 132f (Doutorado em Educação Física) - Universidade São Judas Tadeu, São Paulo, 2014.

JACKSON, S. et al. Psychological correlates of flow in sport. Journal of Sport and Exercise Psychology, Champaign, v. 20, p. 358-378, 1998.

JACKSON, S. Toward a conceptual understanding of the flow experience in elite athletes. Research Quarterly for Exercise and Sport, London, v. 67, p. 76-90, 1996.

KAWABATA, M.; EVANS, R. How to classify who experience flow from who did not based on the flow state scale-2 scores: a pilot study of latent class factor analysis. The Sport Psychologist, Champaign, v. 30, p. 267-275, 2016. 
KOEHN, S.; MORRIS, T.; WATT, A. P. Flow state in self-paced and externally-paced performance contexts: an examination of the flow model. Psychology of Sport and Exercise, Amsterdam, v. 14, p. 787-795, 2013.

KOEHN, S.; MORRIS, T.; WATT, A. P. Imagery intervention to increase flow state and performance in competition. The Sport Psychologist, Champaign, v. 28, p. 48-59, 2014.

MACÍAS, M. A. F. et al. Flow y rendimiento en corredores de maratón. Revista de Psicología del Deporte, Palma de Mallorca, v. 24, n. 1, p. 9-19, 2015.

MASSARELLA, F. L.; WINTERSTEIN, P. J. A motivação intrínseca e o estado mental flow em corredores de rua. Movimento, Porto Alegre, v. 15, n. 2, p. 45-68, 2009.

MIRANDA JUNIOR, M. V. et al. Análise do flow-feeling no tênis. Revista de Educação Física/UEM, Maringá, v. 23, n. 4, p. 607-615, 2012.

MIRANDA, R.; BARA FILHO, M. G. Construindo um Atleta Vencedor: uma abordagem psicofísica do esporte. Porto Alegre: Artmed, 2008.

OLIVEIRA, H. Z.; GOMES, V. F. P.; MIRANDA, R. O estado flow em jogadores jovens de basquetebol. Psicologia em Estudo, Maringá, v. 20, n. 1, p. 95-106, 2015.

OLIVEIRA, H. Z.; MIRANDA, R. O estado de flow no basquetebol em categorias de base: uma análise da interferência da idade e do tempo de prática. Revista de Educação Física/UEM, Maringá, v. 26, n. 1, p. 89-96, 2015.

RYAN, R.; DECI, E. Self-determination theory and the facilitation of intrinsic motivation, social development, and well-being. American Psychologist, Washington, v. 55, n. 1, p. 68$78,2000$.

SAMULSKI, D. M. Motivação. In: SAMULSKI, D. M. Psicologia do esporte: conceitos e novas perspectivas. 2. ed. Barueri, SP: Manole, 2009. p. 167-192.

SWANN, C.; CRUST, L.; VELLA, S. New Directions in the Psychology of Optimal Performance in Sport: flow and clutch states. Current Opinion in Psychology, Amsterdam, v. 16, p. 48-53, 2017.

SWANN, C. et al. A systematic review of the experience, occurrence, and controllability of flow states in elite sport. Psychology of Sport and Exercise, Amsterdam, v. 13, p. 807-819, 2012 .

SWANN, C. et al. Exploring the interactions underlying flow states: a connecting analysis of flow occurrence in European Tour golfers. Psychology of Sport and Exercise, Amsterdam, v. 16, p. 60-69, 2015.

SWANN, C. et al. Psychological states underlying excellent performance in professional golfers: "Letting it happen" vs. "making it happen". Psychology of Sport and Exercise, Amsterdam , v. 23, n. 101-113, 2016. 
THOMAS, J. R.; NELSON, J. K.; SILVERMAN, S. J. Métodos de pesquisa em atividade física. 5 ed. Porto Alegre: Artmed, 2007.

VIEIRA, L. F. et al. Estado de fluxo em praticantes de escalada e skate downhill. Motriz, Rio Claro, v. 17, n. 4, p. 591-599, 2011.

Recebido em: 22/05/2017

Revisado em: 04/06/2018

Aprovado em: 14/06/2018

Endereço para correspondência:

danielpires@ufpa.br

Daniel Alvarez Pires

Universidade Federal do Pará, Faculdade de Educação Física.

Avenida dos Universitários

Jaderlândia

68746360 - Castanhal, PA - Brasil 